\title{
Paradigm towards ensuring of energy saving in the crisis management conditions in the aspect of sustainable environmental development
}

\author{
Nataliia Kuzmynchuk ${ }^{1}$, Tetiana Kutsenko ${ }^{1}$, Olga Zyma ${ }^{2}$, Oleksandra Terovanesova ${ }^{1}$, and \\ Iryna Bachkir ${ }^{3 *}$ \\ ${ }^{1}$ V. N. Karazin Kharkiv National University, 4 Svobody Sq., Kharkiv, 61022, Ukraine \\ ${ }^{2}$ Simon Kuznets Kharkiv National University of Economics, 9-a Nauki R-t, 61166, Kharkiv, Ukraine \\ ${ }^{3}$ Kremenchuk Mykhailo Ostrohradskyi National University, 20 Pershotravneva Str., 39600, \\ Kremenchuk, Ukraine
}

\begin{abstract}
The aim of the article is to develop the theoretical foundations of energy saving as a factor in achieving the goals of sustainable environmental development on the principles of crisis management. The growth in the volume of energy consumption in the world is accompanied by the increase in anthropogenic pressures on the environment and humans and actualizes the issue of achieving sustainable environmental development of the society while reducing the resources use and solving environmental problems. Based on the use of economic and mathematical methods it is substantiated the feasibility of household consumers to use three-phase meters and it is proved the need to switch to a combined electric heating system which allowed to stimulate the electricity users to use electricity economically and solve the problem of load leveling in accordance with the crisis management principles. In practice, the implementation of the proposed activities will make it possible to activate the transition of household consumers to a differentiated tariff and achieve the goals of crisis management and environmental efficiency.
\end{abstract}

\section{Introduction}

Anti-crisis management of the country's economy in the system of the activities to implement the priority goals of sustainable environmental development is based on the need to solve the problems in the basic sectors of the domestic economy, in particular in the energy sector. The high level of energy intensity of the national economy in comparison with many European countries, and the low energy efficiency of the electric power sector as a whole is the important problem of the domestic energy sector, requiring an urgent solution in terms of achieving the goals of sustainable environmental development and reducing the negative impact on the environment. In accordance with the global trends and regularities of the energy sector development, there is a significant increase in demand for electric energy and energy resources, the high volatility of prices for energy resources is increasing, and much attention is paid to the environmental component of the economic

* Corresponding author: chkutsenko@gmail.com 
development [1-3]. Implementation of contemporary approaches to increasing energy efficiency and introducing the energy saving mechanisms allows us to overcome the systemic crisis of the domestic economy in the context of ensuring sustainable environmental development and maintaining a balance of interests of individual consumers and the state as a whole in the economic, environmental and social spheres.

Positively evaluating the research results presented in national and foreign scientific literature there is a need for systematic study of the problem of achieving sustainable environmental development in terms of achieving high energy efficiency and implementation of energy saving measures in a crisis of the national economy, the need to address social and environmental problems on the principles of crisis management [4-6]. The importance of solving these problems has led to the need for a detailed analysis of the actions to improve energy efficiency as a basis for achieving sustainable development goals and solving the current socio-environmental and economic problems in the modern society.

The aim of the study is to develop the theoretical foundations of energy conservation as a factor in achieving the goals of sustainable environmental development, reducing the anthropogenic pressures on the natural environment in the context of a circular economy based on the principles of anti-crisis management.

\section{Materials and Methods}

Ukraine supported the ideas of sustainable development, which were proclaimed in the resolution of the United Nations General Assembly of September 25, 2015 No. 70/1 of the global goals of sustainable development until 2030 [7], however, it has not yet been formed a holistic understanding of the mechanisms for their implementation. The solution of such a goal of sustainable development as sustainable consumption and production is possible through the transition to a circular economy is the system of production and consumption based on the most efficient use of the natural resources, minimization of production waste and the impact of negative external factors on the environment [8-12]. The circular economy model is actually an integration of economic, social and environmental policies and is focused on a comprehensive solution to environmental, socio-economic problems by reducing the resource intensity of GDP, increasing employment and increasing GDP growth rates [7, 13]. In this case, energy efficiency acts as an influential factor in ensuring sustainable environmental development and implementing the principles of a circular economy by preserving and increasing natural capital based on managing limited reserves and balancing the flows of renewable resources in the context of crisis management.

Energy efficiency is the effective and cost-effective tool for sustainable environmental development of the economy as a whole and allows to reduce the investment need, to increase competitiveness and consumer welfare and reduce anthropogenic pressure on the environment by reducing greenhouse gas emissions and local air pollution.

\section{Results and discussion}

The implementation of energy efficient and energy saving technologies within the framework of anti-crisis management by the cycle optimizing of the technological process from energy production, transportation, distribution to final consumption is to ensure the reliability of energy supply and its accessibility for citizens. It should be noted that energy saving can be ensured only if the consumer is interested in the efficient use of energy through the use of multi-zone meters for owners who have extended the validity of the relevant tariffs by 31.03 .2021 [5]. 
It is carried out the payback analysis on the base of the method of discounting the project of combined heat supply with a residential consumer in the role of the investor and the analysis of the sensitivity of the model to payback periods in the range of the proposed tariff menu based on the establishment of such tariffs so that combined heat supply for a residential consumer is implemented. Net discounted cost, from an economic point of view, is as follows:

$$
N P V=-K_{e}+\sum_{t=1}^{n} \frac{C F_{t}}{(1+i)^{t}},
$$

where $K_{e}$ - costs of installing two (three) zone meter and re-equipment of the power grid; $C F_{t}$ - savings for the 1-th year from switching to the night tariff; $\mathrm{i}$ - the rate of return; $n$ - the deadline for the validity of the differential zone tariff project, during years.

Since 2000 , there has been a tendency to increase the electricity tariff for household consumers which can be regarded as the important factor in encouraging consumers to switch to a differentiated tariff depending on the period of time. Therefore, we note that the average geometric increase in the cost of the electricity tariff for the period 2000-2020 was chosen for the calculations. It is proposed the analysis to be conducted according for two scenarios of household consumer costs for the installation of a three-phase meter is optimistic and pessimistic. Savings $C F_{t}$ from the transition to zone ratification depends on the difference in tariff coefficients, the volume of electricity consumed for the year $t$, transferred to the «night» tariff, and the base tariff, taking into account the annual increase in the cost of electricity. The following formula is proposed:

$$
C F_{t}=\left(k_{d}-k_{n}\right) \cdot V \cdot a^{t-1} \cdot \Delta
$$

$\mathrm{k}_{\mathrm{d}}$ - daily tariff; $\mathrm{k}_{\mathrm{n}}$ - night tariff; $V$ - the base cost of $1 \mathrm{kWh}$ (with the tariff coefficient $k=1$ ) at the beginning of the first year; $a^{t-1}-$ the coefficient of the average annual increase in the base cost of $1 \mathrm{kWh}$ (at the tariff coefficient $\mathrm{k}=1$ ), starting from the second year; $\Delta-$ the annual volume of electricity, transferred to the night consumption period. This value does not change since the expected increase in the number of electrical appliances in a household is offset by a constant increase in their energy efficiency. The payback period is found for:

$$
N P V=0
$$

The dependence of the value of the night tariff coefficient on the number of years of full payback, taking into account (4) - (6) with $k_{d}=1$, will look like this:

$$
\begin{aligned}
k_{n}(t) & =k_{d}-\frac{K_{e}}{V \cdot \Delta \cdot f(t)} \\
f(t) & =\sum_{t=1}^{n} \frac{a^{t-1}}{(1+i)^{t}}
\end{aligned}
$$

The annual amount of electricity transferred to the night consumption period is calculated by the following formula:

$$
\Delta=t_{s} \Delta_{s}+t_{o s} \Delta_{o s}+t_{w} \Delta_{w}
$$


where $\Delta_{s}, \Delta_{o s}, \Delta_{w}$ - daily transferred to night electricity consumption $(\mathrm{kW} / \mathrm{h})$ in summer, autumn-spring and winter periods, respectively; $t_{s}, t_{o s}, t_{w}$ - duration (days) of summer, autumn-spring and winter periods, respectively.

Depending on the completeness of the equipment of the model consumers-regulators with electric receivers, the optimistic and pessimistic scenarios were considered in terms of the amount of expenses for strengthening the subscriber supply of electricity in the house. The optimistic scenario assumes that a household consumer has an electric heat storage heating system and the costs of the project include: installing a three-zone meter, purchasing a panel, strengthening the electrical input for households, installing a cable, unforeseen expenses. Under the pessimistic scenario, all the above costs are considered, plus the purchase and installation of an electric heating system.

The article analyzes the influence of night tariff coefficients $\left(k_{n}\right)$ on the payback period. The analysis in the framework of the optimistic scenario revealed that the payback periods for the different types of consumers-regulators with the existing reducing coefficient of the night tariff $\left(k_{n}=0,4\right)$ are very short. Thus, consumers-regulators of the type «B-1» will reimburse the costs of the project for 4 years, type «B-2» - for 2,7 years, and type «B-3»less than a year.

Graphical modeling of payback periods is with the existing night tariff coefficient in the optimistic scenario. The analysis under the pessimistic scenario shows that with the existing decreasing nightly tariff coefficient, the payback period for the types of consumersregulators is as follows. It is established that the payback of the project for the consumer type «B-1» is not provided in a reasonable time and for the household consumer type «B-2» occurs after a reasonable period of 10 years, $100 \%$ payback for the consumer type «B-3» occurs for quite a short period -4 years which is a very optimistic result.

Thus, the efficiency of the consumer's investment in the project which provides them with the technical ability to increase the installed capacity of electrical receivers and participate in the regulation of electrical load the greater, the higher the amount of electricity used, the consumption of which can be delayed at night [14-16]. Improving energy efficiency and ensuring energy security will help reduce risks in the activities of energy distribution companies [17-19]. It should be noted that without introducing additional capacity on the basis of the existing elements of the energy structure it is possible to implement the combined heat supply with the investor represented by the household consumer.

As a result, the elements of the existing energy structure activate the potential which is idle in the form of nuclear power units. The energy system, in turn, becomes controlled by the capacity of the household consumer type «B», and the household consumer receives the understated coefficient of the night tariff for electricity on the basis of the contract. The next step was to develop proposals for the choice of night coefficient $\left(k_{n}\right)$ for the tariff schemes to encourage household consumers of all selected categories to implement the electric heating system.

To enable the implementation of the project by consumers of type «B-1» and «B$2 »$, tariff schemes were developed setting the coefficients for which are equal to $k_{n}=$ 0,2 and $k_{n}=0,6$, respectively. In Figure 1, it is proposed to reduce $k n$ for a B-1 type household consumer to 0,2 , which will allow him to reimburse the project costs in the very distant future - for 19 years. Modeling the choice of coefficient $k_{n}$ for home ownership B-3. 


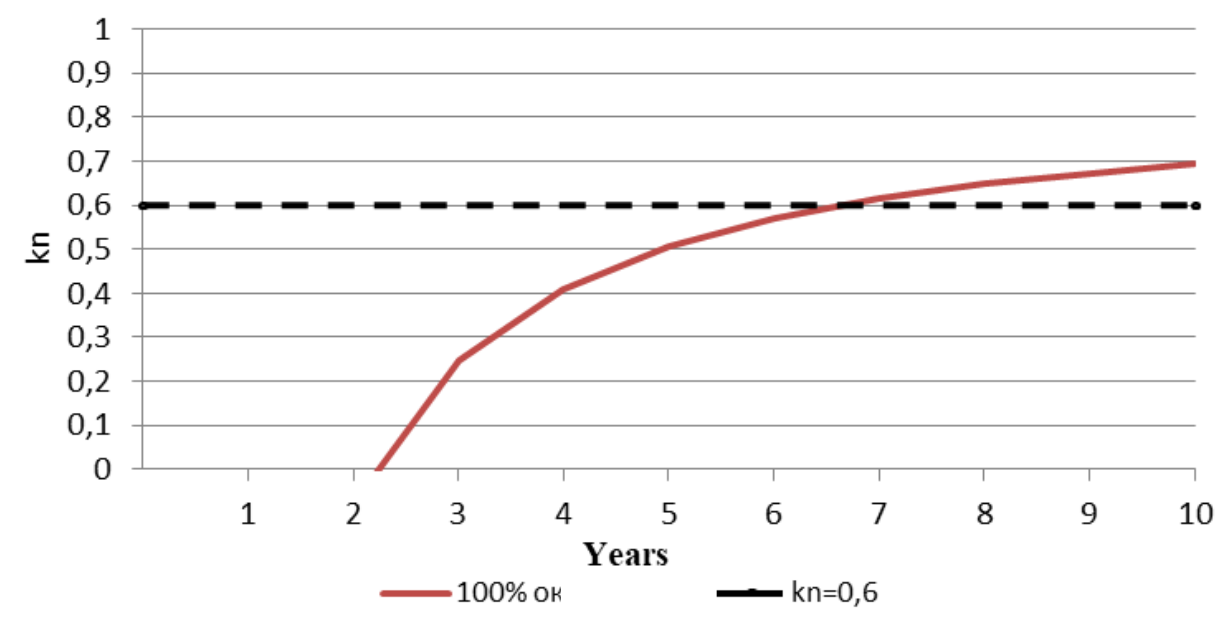

Fig. 1. Justification of the choice of the $k_{n}$ coefficient for the tariff schemes designed to stimulate consumers of category «B-3» to involve in the transition to the differentiated tariff.

In Fig. 2 it is substantiates the proposal to increase the reduction factor of the night tariff for the B-3 consumer to 0,6 which will allow the energy company to support the B-1 consumer by implementing the so-called cross-subsidization. Modeling the choice of coefficient $k_{n}$ for home ownership B-2.

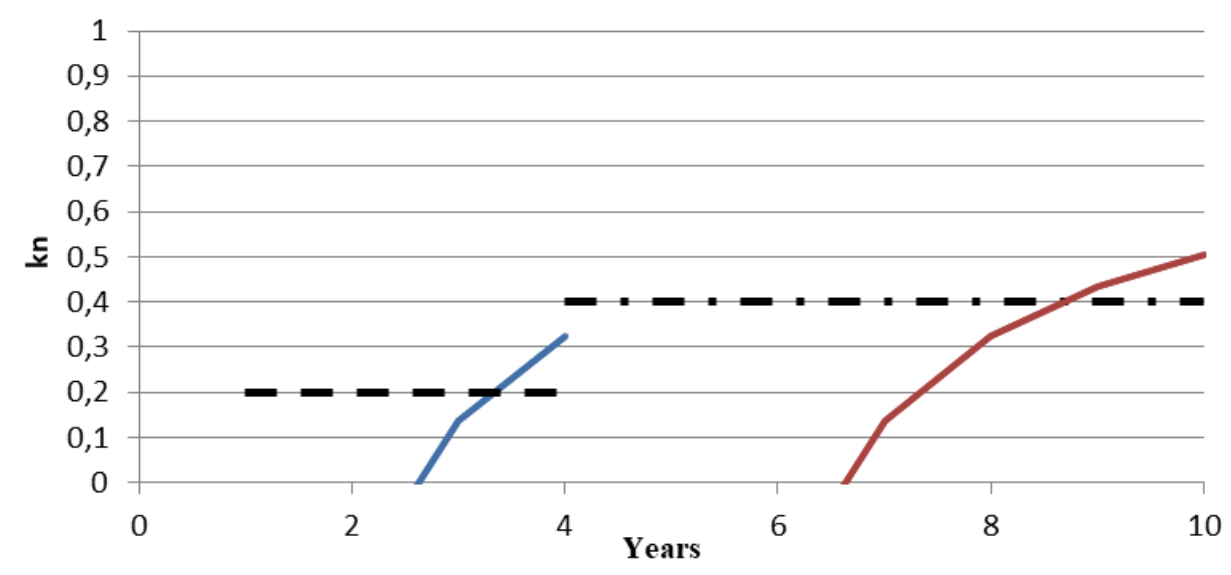

Fig. 2. Justification of the choice of the coefficient $k_{n}$ for tariff schemes designed to stimulate consumers of category «B-2» to switch to a differentiated tariff.

In Fig. 2 it is justified the choice of the reduction coefficient for the domestic consumerregulator by the type «B-2». that is, for this type of household consumer it is proposed to introduce a two-stage tariff scheme where the stages are negotiated by the percentage of payback before time with its own decreasing coefficient $\left(k_{n}\right)$ :

- the first stage is a reduction of the night tariff coefficient to 0,2 for 4 years, which allows to recoup the project of the combined (electric) heating system by $50 \%$;

- the second stage is a $100 \%$ payback of the project with a night coefficient of 0,4 which predicts the final payback date for 8,5 years. 
The practical implementation of the proposed actions will make it possible to activate the transition of household consumers to a differentiated tariff and combine heat and power system [20-22], which will create the preconditions for sustainable environmental development of the domestic economy with an emphasis on solving environmental problems and improving living standards in the context of crisis management.

\section{Conclusions}

The article summarizes the authors' approaches to improving energy efficiency in Ukraine in terms of achieving the goals of sustainable environmental development and the introduction of energy-saving lifestyles on the principles of crisis management, which will significantly improve the environmental situation and reduce anthropogenic pressure on the environment. Energy saving is a promising environmental and economic resource, the use of which at all levels of society creates the basis for the restoration of economic development, improving the quality of life, reducing the eco-destructive impact on the elements of the biosphere. It is substantiated the expediency of installing a three-phase meter, for on the one hand, electricity consumers are stimulated to the economical mode when using electricity and, on the other hand, it allows to equalize the load on the power grid during the day and year.

It is proved that the stimulation of the implementation of energy saving and energy efficiency measures can occur through a massive transition to the differentiated tariff for household consumers and the introduction of a combined electric heat supply system which will reduce their costs for electricity consumption and optimize the amount of energy resources consumed at the level of the national economy. The practical implementation of the proposed measures will contribute to strengthening the country's environmental and energy security, reducing the negative impact on the environment and the sustainability of the socio-economic development of the national economy in the aspect of crisis management.

Prospects for further research are the development and implementation of a mechanism for introducing innovations in the energy sector based on the use of renewable energy sources as a factor in transforming the glob.

\section{References}

1. Smith-Gillespie, A. (2017). Defining the Concept of Circular Economy Business Model.R2 $\pi$, European Union, Brussels, Belgium.

2. Battini, D., Bogataj, M., \& Choudhary, A. (2017). Closed Loop Supply Chain (CLSC): Economics, Modeling, Management and Control.

3. Boulding, K. (1966) The Economics of the Coming Spaceship Earth. In: Jarrett, H., Ed., Environmental Quality in a Growing Economy, Resources for the Future/Johns Hopkins University Press, Baltimore, 3-14.

4. Koval, V., Sribna, Y., Gaska, K. (2019). Energy cooperation Ukraine-Poland to strengthen energy security. E3S Web Conference, 132, 01009. https://doi.org/10.1051/e3sconf/201913201009

5. Cabinet of Ministers of Ukraine (2007). Concept of the National Ecological Policy of Ukraine for the period until 2020. https://www.kmu.gov.ua/npas/95215363

6. Cabinet of Ministers of Ukraine (2019). Decision of December 28, 2020 No. 1325 On amendments to the Resolution of the Cabinet of Ministers of Ukraine dated in June 5, 2019 No. 483. https://www.kmu.gov.ua 
7. Ellen MacArthur (2015). Foundation: Towards a Circular Economy: Business Rationale For An Accelerated Transition. https://www.ellenmacarthurfoundation.org

8. Meadows, D.H., Randers, J., Meadows, D.L., Behrens, W.W. (1972). The Limits to Growth: A Report for the Club of Rome's Project on the Predicament of Mankind. Universe Books.

9. Nguyen, H., Stuchtey, M., \& Zils, M. (2014). Remaking the Industrial Economy. McKinsey \& Company. http://mckinsey.com/business-functions/sustainabilityandresource-productivity/our-insights/remaking-the-industrialeconomy

10. Pauli, G.A. (2010). The Blue Economy: 10 Years, 100 Innovations, 100 Million Jobs. Paradigm Publications.

11. Smol, M., Kulczycka, J., \& Avdiushchenko, A. (2017). Circular economy indicators in relation to eco-innovation in European regions. Clean Technologies and Environmental Policy, 19(3), 669-678.

12. Van der Straaten, J., \& Van den Bergh, J.C. (1994). Towards sustainable Development: Concepts, Methods, and Policy. California: Island Press.

13. Vanner, R., Bicket, M., \& Withana, S. (2014). Scoping Study to Identify Potential Circular Economy Actions, Priority Sectors, Material Flows and Value Chains Final Report. Luxembourg: Publications Office.

14. Wilts, H., \& Berg, H. (2017). The digital circular economy: can the digital transformation pave the way for resource-efficient materials cycles? In Brief: Sustainability Impulses from Wuppertal. Wuppertal Institute.

15. Shmygol, N., Schiavone, F., Trokhymets, O., Pawliszczy, D., Koval, V., Zavgorodniy, R., \& Vorfolomeiev A. (2020). Model for assessing and implementing resourceefficient strategy of industry. CEUR Workshop Proceedings, 2713, 277-294.

16. Koval, V., Sribna, Y., Mykolenko, O., \& Vdovenko, N. (2019). Environmental concept of energy security solutions of local communities based on energy logistics. 19th International Multidisciplinary Scientific GeoConference SGEM 2019, 19(5.3), 283290. https://doi.org/0.5593/sgem2019/5.3/S21.036

17. Arsawan, I.W.E., Koval, V., Rajiani, I., Rustiarini, N.W., Supartha, W.G., \&Suryantini, N.P.S. (2020). Leveraging knowledge sharing and innovation culture into SMEs sustainable competitive advantage. International Journal of Productivity and Performance Management. https://doi.org/10.1108/IJPPM-04-2020-0192

18. Mikhno, I., Koval, V., Shvets, G., Garmatiuk, O., \& Tamošiūnienè, R. (2021). Discussion: Green Economy in Sustainable Development and Improvement of Resource Efficiency. Central European Business Review, 10, 1-15. https://doi.org/10.18267/j.cebr.252

19. Hutsaliuk, O., Koval, V., Tsimoshynska, O., Koval, M., Skyba, H. (2020). Risk Management of Forming Enterprises Integration Corporate Strategy. TEM Journal, 9(4), 1514-1523. https://doi.org/10.18421/TEM94-26

20. Koval, V. (2018). State regulation of energy security in national economy. Economics, Ecology, Socium, 2(3), 57-64. https://doi.org/10.31520/2616-7107/2018.2.3-6

21. Kryzia, D., Kuta, M., Matuszewska, D., \& Olczak, P. (2020). Analysis of the potential for gas micro-cogeneration development in Poland using the Monte Carlo method. Energies, 13(12), 3140. https://doi.org/10.3390/en13123140

22. Olczak, P., Olek, M., Matuszewska, D., Dyczko, A., \& Mania, T. (2021). Monofacial and Bifacial Micro PV Installation as Element of Energy Transition-The Case of Poland. Energies, 14(2), 499. https://doi.org/doi.org/10.3390/en14020499 